\section{China deploys big data to clear smog}

China's Ministry of Environmental Protection is tackling the country's severe air-pollution problems by using a holistic approach to the collection, analysis and quality assurance of vast amounts of data - and making the information publicly accessible.

The ministry has improved sharing of data from multiple sources. Satellite data are used to analyse and predict general air quality and pollution by particulate matter. Drones monitor pollution discharges, measure air quality and assess the effectiveness of environmentalprotection programmes. Citizens contribute widely by promptly reporting pollution episodes.

The ministry provides the platform to harvest, manage and publish these data. It also merges weather and air-quality information with chemical modelling to assist early-warning systems for potentially severe smog incidents.

Bo Zhang Information Center, Ministry of Environmental

Protection, China.

Robert M. Hughes Oregon State University, USA.

zhangbo@mep.gov.cn

\section{Boost prospects for women scientists}

India is set to become the world's most populous nation and has the potential to be a scientific powerhouse. To speed the process, it will need to develop innovative solutions for advancing women's careers and participation in science, technology, engineering, mathematics and medicine (STEMM).

Despite commendable initiatives by government departments and science academies (see R. Godbole and R. Ramaswamy in Women in Science and Technology in Asia; AASSA, 2015), India so far has no comprehensive national programme for encouraging institutions to undertake active gender-equality measures. It could learn from schemes elsewhere, such as the Equality Challenge Unit's Athena SWAN Charter in Britain and Ireland (go.nature.com/2jnbvt4) and the government-supported Science in Australia Gender Equity (SAGE) pilot initiative led by Australian science academies (go.nature.com/2jz2wyk).

A workshop convened last year by the Australian, Indian and UK governments resulted in cross-national recommendations for achieving gender equality in STEMM (see go.nature. com/2kg2hkt). We hope that these will spur efforts by the scientific community and the government of India to implement them in cooperation with similar initiatives in other countries.

Pavel V. Ovseiko University of Oxford, UK.

Rohini M. Godbole Indian Institute of Science, Bangalore. Jane Latimer George Institute for Global Health, University of Sydney, Australia.

pavel.ovseiko@medsci.ox.ac.uk Competing financial interests declared (see go.nature.com/2k7ar2h).

\section{Axe science hype from social media}

The widespread dissemination of inaccurate, overstated or incomplete science on social media fuels pseudoscience, conspiracy theories and distrust in science itself. Researchers can help to prevent poor-quality science from influencing public opinion, policymaking and research-funding decisions by carefully vetting content to ensure that the information is trustworthy before sharing it (see also P. Williamson Nature 540, 171; 2016).

Fake scientific news is often generated by the misguided transformation of peer-reviewed papers into headline-grabbing stories. Social-media metrics are based on the number of followers and 'likes', not on quality. We therefore caution against using such alternative metrics (altmetrics) in funding applications (Nature 516, 147; 2014) and for career advancement (R. Kwok Nature 500, 491-493; 2013), which could encourage researchers to share erroneous hyperbolized content.

By using social media to swiftly identify sensationalism, evaluate the quality of the original source and report inaccuracies in headlines and story content, scientists can help to counter the dangerous spread of misinformation.

James M. Smoliga High Point University, North Carolina, USA. Corinne J. Kendall North Carolina Zoo, Asheboro, North Carolina, USA.

jsmoliga@highpoint.edu

\section{Charles Henry Turner remembered}

In these alarming times for the progress of US science and diversity, I wish to mark 150 years since the 3 February birth of Charles Henry Turner (18671923), a shamefully neglected African American scientist.

In 1907, Turner became the third African American at the University of Chicago, Illinois, to be awarded a $\mathrm{PhD}$ (in zoology). He published more than 70 papers in fields as diverse as avian morphology, natural history, insect navigation, education and civil rights including the first paper by an African American in Science (C. H. Turner Science 19, 16-17; 1892). Turner discovered that foraging ants make an exploratory circling movement on returning to their nests, which the French naturalist Victor Cornetz named tournoiement de Turner (Turner circling) in his honour in 1910 (see also go.nature.com/2khjyux).

Unable to secure an academic job despite his publication record,
Turner did most of his research while teaching on the meagre salary paid in African American high schools (W. S. Savage J. Negro Hist. 22, 335-344; 1937), without proper lab facilities, a library or graduate students.

I suggest that Turner's contributions should be taught in schools and universities to inspire more students from under-represented groups to enter the scientific, engineering and medical disciplines.

Charles I. Abramson Oklahoma State University, Stillwater, USA charles.abramson@okstate.edu

\section{Journals, do your own formatting}

The idiosyncratic formats required by individual journals make submitting a manuscript a major time sink (see Q. Guo Nature 540, 525; 2016). This is invariably amplified by another wave of amendments after acceptance. Authors are becoming, in effect, desktop publishers.

In the 'good old days', one placed a manuscript in an envelope, found a postage stamp somewhere in the desk drawer and located a post box. If the paper was accepted, a few queries from the subeditor would need attention, and a perfectly decent product would emerge. Journal staff took responsibility for the full production process.

At a time when other pressures on researchers are inexorably increasing, I suggest that journals should take back the formatting baton. This seems more than justified in view of the burgeoning publication charges many of them impose. John P. Moore Weill Cornell Medical College, New York, USA. jpm2003@med.cornell.edu

CONTRIBUTIONS

For submission details, see http://go.nature.com/ cmchno 